\title{
Subjetividade: uma análise pautada na Psicologia histórico-cultural
}

\author{
Subjectivity: an analysis based in the historical-cultural Psychology \\ Subjetividad: un análisis pautado en la Psicología histórico-cultural
}

\author{
Elis Bertozzi Aita* \\ Marilda Gonçalves Dias Facci**
}

\begin{abstract}
Resumo
Este artigo é resultado do desenvolvimento de investigação que ocorreu por meio de pesquisa bibliográfica sobre a concepção de subjetividade na perspectiva da Psicologia histórico-cultural e pela análise de 51 artigos selecionados na biblioteca eletrônica Scielo pelas palavras-chave "subjetividade" e "educação". O objetivo deste trabalho é apresentar consideraçóes sobre as diversas formas de compreender a subjetividade presentes nos artigos consultados e a análise acerca da compreensão da subjetividade com base na Psicologia históricocultural. Por meio desta pesquisa, pôde-se observar que existem várias compreensões acerca do conceito de subjetividade, mesmo entre aqueles autores que abordam o tema sob uma mesma perspectiva teórica. Diante disso, destaca-se a importância de se compreender o que é subjetividade, valendo-se da lógica dialética, considerando o quanto esta é constituída por meio das relações sociais de produção.
\end{abstract}

Palavras-chave: subjetividade; Psicologia histórico-cultural; dialética.

\begin{abstract}
This work is the result of an investigation developed by means of literature research on the conception of subjectivity in the light of HistoricalCultural Psychology and the analysis of 51 articles selected on Scielo (2008) electronic library on the keywords "subjectivity" and "education". The aim of this paper is to present considerations on the different ways of understanding the subjectivity found in the articles examined and the analysis of the understanding of subjectivity based on the HistoricalCultural Psychology. This research enabled the observation of different
\end{abstract}

\footnotetext{
Discente do curso de Psicologia da Universidade Estadual de Maringá. Endereço: Rua Líbero Badaró, 261, apto 104, CEP 87030-080, Zona 07, Maringá-PR. E-mail: lis_aita@hotmail.com.

** Pós-doutoranda no Instituto de Psicologia da Universidade de São Paulo-USP, doutora em Educação Escolar pela Universidade Estadual Paulista (Unesp - Araraquara), professora do Departamento de Psicologia e do Programa de Pósgraduação em Psicologia da Universidade Estadual de Maringá. Endereço: Rua Parque do Horto, 124, CEP 87.060-285 - Maringá-PR. E-mail: mgdfacci@uem.br.
} 
ways of understanding the concept of subjectivity, even among those authors who address the subject under the same theoretical perspective. Thus, the importance of understanding subjectivity is highlighted in the light of dialectical logic, considering how much it is consolidated through social relations of production.

Keywords: subjectivity; historical-cultural Psychology; dialectics.

\section{Resumen}

Este artículo es el resultado del desarrollo de una investigación realizada a través de una investigación bibliográfica sobre la concepción de subjetividad en la perspectiva de la Psicología Histórico-Cultural y por el análisis de 51 artículos seleccionados en la biblioteca electrónica SciELO (2008) a partir de las palabras clave subjetividad y educación. El objetivo de este artículo es presentar consideraciones sobre las diversas formas de comprender la subjetividad presentes en los artículos consultados y el análisis acerca de la comprensión de la subjetividad basada en la Psicología Histórico-Cultural. Por medio de esta investigación, se pudo observar que hay varias comprensiones con respecto al concepto de subjetividad, incluso entre aquellos autores que abordan la temática bajo la misma perspectiva teórica. Ante esto, se señala la importancia de comprender qué es subjetividad valiéndose de la lógica dialéctica, considerando lo cuanto ésa es constituida por medio de las relaciones sociales de producción.

Palabras clave: Subjetividad; Psicología Histórico-Cultural; Dialéctica.

\section{Introdução}

E ste artigo é resultado do desenvolvimento do projeto de pesquisa intitulado "O conceito de subjetividade na atualidade: uma análise a partir da Psicologia histórico-cultural". A definição pelo tema da pesquisa deu-se pelo fato de observamos que o termo subjetividade tem sido bastante utilizado na atualidade, em produçóes de diversas áreas do conhecimento, e nosso interesse foi analisar até que ponto a compreensão da subjetividade se pautava nos pressupostos da Psicologia histórico-cultural, com base no método histórico-dialético.

A realização deste projeto de pesquisa ocorreu por meio de pesquisa bibliográfica sobre a concepção de subjetividade na perspectiva da Psicologia histórico-cultural e pela leitura e análise de artigos que tratavam 
da subjetividade e da educação disponíveis na biblioteca eletrônica Scielo . Nosso objetivo, portanto, consiste em apresentar, neste artigo, consideraçóes sobre as diversas formas de compreender a subjetividade presentes nos artigos consultados e a análise acerca da compreensão da subjetividade com base na Psicologia histórico-cultural.

Partiremos da compreensão de subjetividade proposta por Leontiev (1978/1983, p. 44), como "uma propriedade do sujeito ativo". Um fator que torna o sujeito único, singular. Uma subjetividade constituída com base na realidade material, na relação entre os homens, conforme veremos no próximo item.

O desenvolvimento do psiquismo e da subjetividade na perspectiva da Psicologia histórico-cultural

O desenvolvimento da subjetividade tem sido compreendido como um processo natural, desvinculado das condições históricas, como se ocorresse em etapas universalizadas, pautadas, muitas vezes, apenas na maturação biológica, não dando conta de explicar o homem concreto, síntese das relações sociais, como propõe uma visão marxista.

Por meio da lógica dialética, Saviani (2004) procura compreender o conceito de subjetividade segundo Marx. Evidencia que, para Marx, "o conteúdo da essência humana reside no trabalho.... o ser do homem, a sua existência, não é dada pela natureza, mas é produzida pelos próprios homens" (Saviani, 2004, p. 28). O homem constrói, assim, sua essência em sua existência, em sua atividade prática chamada trabalho. $\mathrm{O}$ homem difere de outros animais nesse sentido, visto que os animais, em geral, para garantirem sua existência, precisam apenas adaptar-se à natureza, e ela garante sua sobrevivência. Já, para o homem, não basta adaptar-se à natureza, é preciso transformá-la. Essa transformação ocorre por meio do trabalho.

A análise de Saviani (2004) evidencia que Marx, nas teses sobre Feuerbach, aponta claramente sua concepção de essência humana, de subjetividade e sua definição de homem. Na VI tese, Marx (1845/1998, p. 101) afirma que "a essência humana não é uma abstração inerente ao indivíduo singular. Em realidade, é o conjunto das relações sociais”. Para Saviani, Marx deixa claro, nessa tese, sua posição em relação à subjetividade humana, nela "já se encontra a definição de homem, vale dizer, do sujeito humano, do indivíduo, como o conjunto de relações sociais, na qual se encerram a síntese do complexo de reflexões e as análises constitutivas da concepção marxiana da

\footnotetext{
SCIELO. Scientific Electronic Library On-line. Recuperado em 15 de abril de 2008 de http://www.scielo.br.
} 
subjetividade" (Saviani, 2004, p. 36). Marx, segundo Saviani (2004), coloca a essência humana não como algo universal e desligado da existência, e sim como, fundamentalmente, um produto das relações sociais de produção, uma essência construída com base em uma existência prática.

O desenvolvimento do homem é, portanto, um processo histórico e social, visto que "o homem é um ser de natureza social, que tudo o que tem de humano nele provém de sua vida em sociedade, no seio da cultura criada pela humanidade" (Leontiev, 1978/2004, p. 279, grifos do autor). O homem só se torna homem, só se humaniza, enquanto se apropria dos mediadores construídos culturalmente, dos conhecimentos construídos pela humanidade ao longo de seu desenvolvimento sócio-histórico. "Cada indivíduo aprende a ser homem. O que a natureza lhe dá quando nasce não lhe basta para viver em sociedade. É-lhe ainda preciso adquirir o que foi alcançado no decurso do desenvolvimento histórico da sociedade humana" (Leontiev, 1978/2004, p. 285 , grifo do autor). Cada geração começa sua vida em um mundo constituído de significados e de objetos construídos pelas gerações anteriores e se apropria dessas objetivações por meio do trabalho.

Dessa forma, o sujeito desenvolve as características especificadamente humanas à proporção que internaliza o trabalho social, o modo de pensar e agir cristalizado na sociedade na qual está inserido. Sem o processo de transmissão de conhecimentos e de comunicação, seria impossível a continuidade do processo histórico, visto que as gerações seguintes não teriam acesso ao desenvolvimento histórico-cultural da humanidade.

Segundo Leontiev (1978/2004), os indivíduos, para se humanizarem, precisam se apropriar da cultura e dos mediadores culturais criados pela humanidade. Portanto o homem só se torna homem ao apropriar-se do mundo, e a constituição da sua subjetividade caminha desse ir e vir do mundo interno para o mundo externo, numa relação dialética entre objetividade e subjetividade.

Teoriza Vigotsky (1931/2000) que o comportamento de um adulto culturalizado é o resultado de dois processos distintos do desenvolvimento psíquico: por um lado, é um processo biológico de evolução das espécies animais que conduziu à aparição do Homo sapiens; por outro lado, é um processo histórico, graças ao qual o homem primitivo se converteu em um ser culturalizado. Ambos os processos, biológico e cultural, estão presentes de forma separada na filogênese, duas linhas independentes de desenvolvimento. Porém, na ontogênese, esses processos estão unidos, formando um processo único. No desenvolvimento ontogênico da criança, estão presentes os dois 
tipos de desenvolvimento psíquico que existem de maneira separada na filogênese, ou seja, estão presentes tanto o desenvolvimento biológico como o histórico.

O homem constitui sua subjetividade mediante o processo de apropriação dos conhecimentos construídos historicamente, desenvolvendo, assim, suas funções psicológicas superiores, tais como raciocínio lógico, pensamento abstrato, capacidade de planejamento, entre outras funções. Esse é um aspecto fundamental para o desenvolvimento da subjetividade e está assentado, também, na relação com outros homens. Vigotsky (1933/1988) assevera que toda função psicológica superior aparece em dois planos, sendo primeiramente interpsíquica (nas atividades coletivas e sociais), para depois tornar-se intrapsíquica (como propriedades internas do pensamento), ou seja, aparece no plano externo e é internalizada.

Deve-se ressaltar que, quando o autor russo refere-se a algo externo, está querendo designar algo eminentemente social. Para Vigotsky (1931/2000), o fundamento de todas as funções psicológicas superiores são as relações humanas, sua gênese é social. Dessa forma, o indivíduo se constitui a partir do outro, desenvolvendo-se em um específico contexto sócio-histórico-cultural.

Vigotsky (1931/2000) destaca que tanto a constituição da personalidade como um todo do sujeito até o desenvolvimento de cada função psicológica superior devem ser entendidos desta forma, com base no processo de internalização das construções sociais. "Todas as funções psíquicas superiores são relações interiorizadas de ordem social, são o fundamento da estrutura social da personalidade. Sua composição, estrutura genética e modo de ação, em uma palavra, toda sua natureza é social" (Vigotsky, 1931/2000, p. 15, tradução nossa).

Vygotski e Luria (1930/1996) afirmam que o desenvolvimento cultural do homem inicia-se com a mobilização das funções psicológicas inatas a partir de seu uso natural. Nesse início de desenvolvimento, ainda é estranha para a criança a ideia de utilizar-se de signos culturais para intervir no meio. Posteriormente, com o auxílio mediador de um adulto, o processo natural passa a converter-se em um processo cultural, visto que a criança começa a apreender os instrumentos e significações construídas socialmente. $\mathrm{O}$ indivíduo, então, começa a utilizar-se desses signos para realizar determinadas tarefas. Esse seria o segundo momento do desenvolvimento cultural, no qual a criança ainda não é capaz de manipular tais instrumentos sozinha, sendo imprescindível a mediação social, já que ela ainda não se apropriou completamente desse aparato cultural (Vigotsky \& Luria, 1930/1996). 
Por meio do processo de mediação, o sujeito vai apreendendo os instrumentos sociais e passa a ser capaz de utilizá-los sozinho, característica do terceiro momento do desenvolvimento cultural, que compreende a internalização dos conhecimentos construídos pela humanidade por parte do sujeito. Nesse processo, os signos externos, sociais, tornam-se internos, e a criança desenvolve suas funções psicológicas superiores (Vigotsky \& Luria, 1930/1996).

Facci (2004) afirma que, para se humanizar, os indivíduos precisam desenvolver as funções psicológicas superiores. $\mathrm{O}$ desenvolvimento delas é o fundamento de toda existência consciente do ser humano; é esse desenvolvimento que permite ao homem superar o reino do biológico pela apropriação da cultura. A formação do indivíduo se dá, sempre, dentro de um processo educativo. Ao se apropriar dos conhecimentos científicos, formando os conceitos, o indivíduo amplia o desenvolvimento das funções psicológicas superiores. Na escola, é a apropriação do conhecimento científico que promoverá o desenvolvimento das funções psicológicas superiores. $\mathrm{Na}$ formação de conceitos, estão presentes todas as funções intelectuais básicas e, desde os estágios iniciais, o desenvolvimento mental da criança ocorre sob a influência constante da comunicação entre a criança e os adultos. A apropriação do mundo permitirá, portanto, que a criança, cada vez mais, torne-se humanizada e constitua a sua subjetividade em uma realidade concreta.

Saviani (2004, p. 46) destaca que os sujeitos se constituem por meio das relações que estabelecem entre si, ou seja, um indivíduo "só pode tornar-se homem se incorporar, em sua própria subjetividade, formas de comportamento e ideias criadas pelas gerações anteriores e retrabalhadas por ele e por aqueles que com ele convive".

Martins (2007) também faz considerações sobre o desenvolvimento do psiquismo a partir do marxismo. Afirma que é preciso compreender o psiquismo em suas relaçóes com o mundo objetivo, compreendendo suas peculiaridades sem desgarrá-lo do mundo material. Destaca ainda que, por meio do materialismo dialético, que se baseia na materialidade dos fenômenos, pode-se compreender o psiquismo como uma estrutura orgânica que, ao mesmo tempo, é reflexo psíquico da realidade. Esse reflexo não é cópia da própria realidade, já que nem a realidade é o reflexo, bem como o reflexo não é a realidade, existindo entre eles uma ligação em que ambos se opõem e coincidem. O psiquismo é determinado pela sua relação com o mundo exterior. Por isso não pode ser considerado como um psiquismo puro ou abstrato, e deve ser entendido como "imagem subjetiva do mundo objetivo, 
isto é, como reflexo psíquico da realidade. O psiquismo e consequentemente o reflexo psíquico resultam de uma relação ativa estabelecida entre o homem e a natureza, são produtos da evolução humana” (Martins, 2007, p. 64).

O homem se humaniza enquanto se apropria da cultura construída histórica e socialmente pelos seus antepassados, o que se torna muito difícil em uma sociedade permeada pela divisão de classe e pelo processo de alienação, conforme discutiremos no final deste artigo. No entanto, antes de adentrarmos nessa discussão, vamos relatar os dados coletados nos artigos consultados.

\section{A compreensão da subjetividade em produções atuais}

Conforme anunciamos na introdução deste artigo, utilizamos como fonte de pesquisa para análise de artigos que tratavam da subjetividade a biblioteca eletrônica Scielo, uma vez que ela permite o acesso a uma produção expressiva de resultados de pesquisas científicas. A seleção dos artigos para a análise ocorreu pela utilização de duas palavras-chave: subjetividade e educação, no mês de abril de 2008. Encontramos e analisamos 51 artigos, sendo que demos ênfase à compreensão da subjetividade naqueles textos que a abordavam com base nos pressupostos da Psicologia histórico-cultural. Os artigos foram lidos na íntegra, fichados e analisados. Após tal análise, foram elaboradas tabelas contendo as informações essenciais dos textos, tais como título; autores(es); ano de publicação; objetivo do texto; conceito de subjetividade expresso no texto; autor(es) que embasam o conceito de subjetividade; relação estabelecida entre a constituição da subjetividade e educação.

É importante destacar, no entanto, que, para a análise dos artigos, foram usados os estudos clássicos da Psicologia histórico-cultural, notadamente L. S. Vigotsky, A. R. Luria, A. N. Leontiev, entre outros autores da mesma escola, assim como autores que discutiam a temática da subjetividade nessa perspectiva teórica.

$\mathrm{Na}$ consulta aos artigos da base Scielo (2008), após a análise dos textos, constatamos que, dos 51 artigos selecionados, 11 (22\%) mencionam o termo subjetividade, porém não fazem uma discussão acerca desse tema, não discorrendo sobre a concepção de subjetividade ou sobre como compreendem o desenvolvimento desta no sujeito. Por isso, os resultados discutidos a seguir baseiam-se nos 40 artigos restantes, que tecem, em algum momento do texto, considerações acerca da subjetividade e ou da forma como ela se constitui. 
Dos textos que discutem a questão da subjetividade, observamos que eles o fazem com base em referenciais teóricos muito diversos, abrangendo uma ampla gama de autores.

Verificamos que quatro (10\%) dos 40 artigos analisados discutem a subjetividade fundamentando-se em Michel Foucault. Seus autores analisam, sobretudo, as relações de poder, destacando sua influência na constituição da subjetividade e nos modos de subjetivação.

Os autores da Escola de Frankfurt foram citados frequentemente nos artigos lidos. Quatro artigos (10\%) referenciaram ao menos um dos autores desta, a saber: Theodor Ludwig Wiesengrund-Adorno, Hebert Marcuse, Walter Benedix Schönflies Benjamin e Jürgen Habermas. Alguns artigos estão inteiramente baseados em Adorno, trazendo uma ampla discussão sobre a subjetividade teorizada com base nesse autor.

Outros autores, mencionados reiteradas vezes nos artigos analisados, foram Gilles Deleuze e Félix Guatarri. Quatro artigos (10\%) se utilizam de conceitos desses autores para compreender a constituição do sujeito; três artigos $(7,5 \%)$ entrelaçam a visão foucaultiana de subjetividade com as formulações teóricas de Deleuze e Guatarri; além disso, um (2,5\%) artigo cita amplamente tanto Deleuze e Guatarri quanto Adorno e Foucault.

Outra corrente teórica encontrada nos artigos pesquisados é a vertente psicanalítica. Quatro (10\%) artigos contemplam, de alguma forma, autores dessa vertente para compreender a subjetividade. Entre os autores citados, estão Sigmund Freud, Jacques Marie Émile Lacan, Donald Woods Winnicott e Erik Homburge Erikson.

De uma forma geral, nesses artigos, observamos que a compreensão de subjetividade nem sempre se aproxima de uma visão marxista, que compreende o homem como síntese das relações sociais, ideia defendida por Saviani (2004). Muitas vezes, toma-se como referência ora fatores internos, ora fatores externos, e não a dialética entre ambos para compreender o tema em questão.

Conforme discutido anteriormente, de acordo com a Psicologia histórico-cultural, são as relações sociais de produção que promovem o desenvolvimento da subjetividade, e a sua formação atrela-se à historicidade dos fenômenos. A subjetividade, portanto, é constituída por fatores internos e externos, na qual a forma de o indivíduo se perceber está relacionada com o modo como os homens estabelecem as relações sociais em um contexto específico, decorrente de condições histórico-sociais. 
Dando continuidade à análise dos artigos, constatamos, ainda, que a concepção teórica da Psicologia histórico-cultural também é utilizada pelos autores dos artigos analisados. Nove (22,5\%) artigos discutem a questão da subjetividade pautados em autores dessa visão teórica. Foi nesses artigos que centramos mais detalhadamente nossa análise, uma vez que a fundamentação teórica adotada para compreender a subjetividade, na pesquisa, procurou ancorar-se na Psicologia histórico-cultural.

Entre os autores dos artigos que afirmam se pautar na Escola de Vigotsky, pode-se considerar, mediante a análise mais detalhada de tais artigos, que não houve um consenso sobre o que é subjetividade e como ela se constitui. Ou seja, até mesmo no interior de uma mesma linha teórica, houve diferentes interpretações e formulações acerca da constituição da subjetividade.

Nos artigos analisados, alguns autores, amparados pela Psicologia histórico-cultural, entendem a subjetividade com base no contexto cultural e simbólico do sujeito, afirmando que ela é construída desde esse contexto. Tais autores preocupam-se, particularmente, com a questão da linguagem e da semiótica, destacando a formação da linguagem como um processo constitutivo da subjetividade. A subjetividade, segundo eles, é formada na relação do sujeito com o outro, processo mediado pela linguagem e pelo contexto histórico-cultural. O psiquismo dos indivíduos se desenvolve pela apreensão de signos e significados, que, por usa vez, são construídos socialmente nas relações entre os homens. Os artigos dessa categoria citam, em sua maioria, Vigotsky e Mikhail Bakhtin.

Já outros autores, também amparados pela Psicologia histórico-cultural, entendem a subjetividade como resultante das relações sociais de produção da vida material. Ao analisarem a formação da subjetividade na sociedade de classes, destacam o processo de alienação, compreendendo que o homem é síntese dessas relaçôes sociais e que a subjetividade se forma por intermédio delas, tal como apregoa Saviani (2004). Esses autores citam, notadamente, Vigotsky e Leontiev, autores que demos destaque no estudo do tema em questão, conforme anunciado anteriormente.

Outro ponto interessante analisado durante a pesquisa e que deve ser destacado é a utilização do termo subjetividade em artigos pertencentes a outras áreas do conhecimento que não a das Ciências Humanas. Durante a investigação, foram encontrados artigos que pertenciam à área de saúde, mais especificamente Odontologia, saúde coletiva, Fonoaudiologia, Nutrição e também Educação Ambiental. Isso demonstra a crescente 
difusão do termo subjetividade que, nesses artigos, é entendido como algo específico do sujeito ou em oposição à objetividade.

O restante dos artigos, a saber, 11 (27,5\%), ou analisa a subjetividade sob outras perspectivas diversificadas ou não apresenta uma visão clara acerca dos autores que estão sendo utilizados para tratar desse tema. Do nosso ponto de vista, tal fato reflete uma ideia, presente na sociedade, de desvalorização dos fundamentos teóricos. Conforme defende Moraes (2003), está havendo um "recuo" da teoria ou mesmo da explicitação de qual teoria embasa a prática e a pesquisa.

Consideramos que a análise dos artigos consultados da base eletrônica Scielo nos possibilitou traçar um panorama sobre como a subjetividade está sendo discutida e conceituada pelos autores contemporâneos, bem como sobre quais são os referenciais teóricos nos quais eles se baseiam para realizar tal discussão. Destacamos que nosso objetivo foi estritamente este, de conhecer o cenário atual referente ao estudo da subjetividade, dando ênfase à compreensão desta com base na Psicologia histórico-cultural, e não o de nos aprofundarmos nas especificidades das conceituações teóricas de cada autor, o que demandaria um estudo aprofundado de cada vertente teórica apresentada nas produções consultadas.

A partir da análise dos artigos, pudemos perceber que o conceito de subjetividade, apesar de ser amplamente utilizado pela Psicologia, tem diversas definições, visto que os autores fazem uso desse termo para designarem fenômenos distintos. A delimitação desse conceito varia conforme a vertente teórica, bem como muda de acordo com a interpretação do autor.

Observamos que muitos autores, ao fazerem uso desse termo em seus artigos, não se preocuparam em determinar a que estavam se referindo quando faziam uso da palavra subjetividade. A partir disso, destacamos a importância de se conceituar o que está se querendo referir quando se faz o uso do termo subjetividade, ou seja, explicitar o que se compreende por subjetividade e como ela se constitui, a fim de não permitirmos que esse termo se naturalize e careça de fundamentação teórica.

Como já destacamos, pudemos analisar que, mesmo os autores que partem de uma determinada perspectiva teórica, como a Psicologia histórico-cultural, elaboram diferentes conceituações acerca do nosso tema de pesquisa. Isso ocorre, do nosso ponto de vista, porque o pensamento de Lev Semióniovich Vigotsky é interpretado de maneiras distintas por autores contemporâneos. 
Nesse sentido, Molon (2003) analisa a constituição do sujeito e da subjetividade na concepção de diferentes autores e na leitura que estes fazem sobre a constituição do sujeito na obra de Vigotsky. Identifica que os autores analisados têm por pressuposto a origem social do homem, mas diferem entre si com relação à maneira como interpretam a relação entre indivíduo e sociedade, e a relação entre a constituição da subjetividade no meio social e individual. A autora destaca que se abre, assim, um debate entre os autores que priorizam o funcionamento intrapsicológico (como, por exemplo, Jaan Valsiner) e aqueles que dão ênfase ao funcionamento interpsicológico (como James $\mathrm{V}$. Wertsch). Temos ainda um terceiro grupo de autores, aqueles que discutem, de forma dialética, a relação entre ambos os aspectos. Cada uma dessas formas de pensar a constituição da subjetividade traz consigo, portanto, diferentes formas de se analisar a constituição do sujeito. Isso ocorre, segundo a autora, devido à identificação ou não do caráter dialético na obra do psicólogo russo. Molon (2003) destaca que a constituição do sujeito e da subjetividade não é esclarecida nem entre os autores que dão ênfase ao aspecto intrapsicológico, nem entre os autores que se preocupam com o interpsicológico, portanto a análise do tema subjetividade é feita com reduçôes de ambas as partes.

Esta análise sobre autores intérpretes de Vigotsky, realizada por Molon (2003), colabora para que possamos compreender por que a própria Psicologia histórico-cultural não tem uma definição única do que é subjetividade e de como ela se constitui.

Além disso, percebemos, nos artigos de modo geral, que algumas concepções de subjetividade são marcadas por uma dualidade, visto que, ao se analisar a subjetividade, exclui-se a objetividade. Alguns autores priorizam a análise do indivíduo, do que é interpsíquico, ao discutirem como a subjetividade se constitui. Já outros autores destacam a sociedade e a objetividade material como determinante da construção subjetiva. É importante, nesse sentido, partir do método dialético para compreender esse conceito, conforme veremos a seguir.

\section{Considerações finais: em defesa de uma compreensão dialética da subjetividade}

Retomando algumas ideias esboçadas no início deste artigo, voltaremos a um a discussão sobre a subjetividade, tomando como fundamentos o método do materialismo histórico e dialético.

Cambaúva e Tuleski (2007) trabalham com uma visão dialética do conceito de subjetividade, dando ênfase à necessidade de superar a lógica 
formal, que separa o mundo objetivo do mundo subjetivo. Dessa forma, as autoras evidenciam que a Psicologia, "ao pensar a subjetividade, exclui a objetividade e, quando se propõe 'objetiva', nega a subjetividade, reduzindo os fenômenos psíquicos a fenômenos de ordem fisiológica" (Cambaúva \& Tuleski, 2007, p. 83). As autoras ressaltam a necessidade de se superar esse dualismo e entendem que tal superação

pode se dar apenas através da lógica dialética, que como método pode auxiliar a entender objetividade e subjetividade como termos que só têm sentido quando referenciados um ao outro, e, portanto, não podem se excluir, pois se constituem na relação de um com o outro (Cambaúva \& Tuleski, 2007, p. 83).

Para a lógica dialética, é preciso ir além da aparência, do imediato, e compreender que o fenômeno empírico é síntese de múltiplas determinações. Compreender a subjetividade com base nessa lógica significa que não se pode partir nem do mundo interno do indivíduo nem do mundo externo. É por essa via que a análise supera a lógica formal e encaminha para o entendimento da unidade dialética entre indivíduo e sociedade.

Pelo que pudemos observar nos artigos analisados em geral, estamos ainda muito longe de ter como guia a lógica dialética para compreender a subjetividade. Confirma Saviani (2004), a solução do impasse entre individualidade e universalidade está na dialética. Segundo ele, a Psicologia não deveria ter como objeto de estudo o indivíduo empírico e sim o indivíduo concreto. É preciso compreender o indivíduo como fruto de relaçōes sociais, como um indivíduo sócio-histórico, conforme anunciamos anteriormente.

A essência humana não é abstrata e nem algo interior de cada indivíduo isolado, mas consiste no conjunto de relações sociais. Dessa forma, não é universal e desligada da existência, e sim, fundamentalmente, um produto das relações sociais de produção, uma essência construída tomando-se por base uma existência prática.

Silva (2007) procura compreender o significado da palavra subjetividade. A autora se pauta em Leontiev, afirmando que, para esse autor, "a palavra subjetividade se refere ao processo pelo qual algo se torna constitutivo e pertencente ao indivíduo; ocorrendo de tal forma que esse pertencimento se torna único, singular" (SILVA, 2007, p. 75). A gênese da subjetividade se dá conforme o sujeito se apropria das relaçóes sociais. Cada indivíduo faz isso de forma única, o que não significa dizer que a gênese da subjetividade está no interior do sujeito. A subjetividade se constitui conforme o sujeito 
internaliza, subjetiva, as relações sociais que são externas a ele, num processo dialético entre o interno e o externo.

Silva (2007) nos lembra de que esse entendimento está de acordo com que conceitua Vigotsky ao descrever o processo de gênese das funções psicológicas superiores. Subjetividade, "em síntese, é o processo de tornar o que é universal em singular, único, isto é, de tornar o indivíduo pertencente ao gênero humano" (p. 76).

É o contexto histórico e cultural no qual o indivíduo está inserido que vai possibilitar a este se desenvolver como sujeito, por meio de uma relação dialética entre objetividade e subjetividade, acrescentam Cambaúva e Tuleski (2007).

Segundo Bock (2001, p. 23), a subjetividade é "concebida como algo que se constitui na relação com o mundo material e social, mundo este que só existe pela atividade humana. Subjetividade e objetividade se constituem uma à outra sem se confundir". Diante disso, defendemos, aqui, a compreensão do desenvolvimento da subjetividade pautada na Psicologia histórico-cultural e nos pressupostos marxistas, visto que consideramos que uma proposta de estudo do psiquismo humano e da subjetividade que se pretenda transformadora não pode desconsiderar que o homem pertence a uma forma determinada de sociedade, e que as particularidades dessa sociedade condicionam a construção dos indivíduos que dela fazem parte.

Para analisar a subjetividade, devemos nos fundamentar na análise do momento histórico e social, enfocando a relação dialética homem-sociedade, como destaca Martins (2007). Esse autor firma que, pelo método dialético, é possível entender a essência humana como movimento, como processo criador, alimentado pelas contradiçóes que a singularidade e a universalidade encerram. Existe uma conexão entre subjetividade e atividade vital do homem, isto é, o trabalho, como afirmamos anteriormente, porque é pela atividade que esse homem constrói a si mesmo e ao mundo. Dessa forma, explica-se o homem e a sociedade pela unidade e luta desses contrários.

Como vivemos em uma sociedade capitalista constituída de classes antagônicas, devemos analisar a essência humana e o desenvolvimento da subjetividade com base na compreensão dessa sociedade. Saviani (2004) destaca que Marx explica o trabalho humano, no atual modo de produção, como sendo um trabalho alienado. Como a essência humana é o trabalho, a essência humana se manifesta de forma alienada, ou seja, "negada nas relações reais que os homens mantêm com os produtos de sua atividade, com sua própria atividade e com os outros homens" (Saviani, 2004, p. 28). 
Saviani $(2004$, p. 29) ressalta que, para Marx, o termo alienação se refere “àqueles que não têm consciência de sua própria situação, que não se sabem como sujeitos da história, aqueles que perderam sua condição de sujeitos de seus próprios atos, de suas próprias obras". Explicita Saviani (2004) que, quanto mais as mercadorias ganham valor, mais se desvaloriza o trabalhador e produtor de tais mercadorias. Nesse processo de produção, conforme o trabalhador produz mercadorias, sua produção, seu trabalho alienado, produz o operário também como mercadoria.

Nessa mesma linha de pensamento, Martins (2007) afirma que o homem objetiva seu trabalho em objetos, materializando-o, para que ele possa se apropriar e enriquecer valendo-se dessas objetivações. Mas, no capitalismo, as objetivaçôes do trabalhador não se constituem em suas apropriações, promovendo um esvaziamento e empobrecimento deste. Essa alienação se dá ainda no processo de produção. $\mathrm{O}$ produto do trabalho torna-se independente do trabalhador, separa-se dele. A objetivação do trabalho humano se torna cada vez mais alienada, fazendo com que o homem não mais se reconheça em seu trabalho.

O desenvolvimento da humanidade não é transmitido aos homens hereditariamente. $\mathrm{O}$ desenvolvimento histórico está fixado em produtos humanos objetivos, e isso tem por consequência que tais aquisiçôes podem separar-se dos homens que as criaram, objetivaram. Ou seja, nem todos os homens conseguem se apropriar das aquisiçóes da humanidade adquiridas com o processo histórico (Leontiev, 1978/2004).

Os homens não são todos iguais, e as enormes diferenças existentes entre eles não se devem fundamentalmente às suas diferenças corporais, aos seus aspectos exteriores e biológicos, e sim são decorrentes "das enormes diferenças e condições do modo de vida, da riqueza da atividade material e mental, do nível de desenvolvimento das formas e aptidões intelectuais" (Leontiev, 1978/2004, p. 293). Ou seja, as consideráveis diferenças existentes entre os homens se dão pela desigualdade econômica existente entre as classes sociais. Por isso, Leontiev (1978/2004, p. 302) destaca que "a destruição das relações sociais assentes na exploração do homem pelo homem, que engendram esse processo, só ela pode pôr fim e restituir a todos os homens a sua natureza humana, em toda a sua simplicidade e diversidade". 


\section{Referências}

Bock, A. M. B. (2001). A Psicologia sócio-histórica: uma perspectiva crítica em Psicologia. In: Bock, A. M. B; Gonçalves, M. G. G.; Furtado, O. (Orgs.). Psicologia sócio-histórica: uma perspectiva crítica em Psicologia. (pp. 15-35). São Paulo: Cortez.

Cambaúva, L. G. \& Tuleski, S. C. (2007). A pseudoconcreticidade do conceito de subjetividade na Psicologia. Revista de Educação, (23), 79-90.

Facci, M. G. D. (2004). Valorização ou esvaziamento do trabalho do professor? Um estudo crítico-comparativo da teoria do professor reflexivo, do Construtivismo e da Psicologia Vigotskiana. Campinas: Autores Associados.

Leontiev, A. N. (1983). Actividade, conciencia e personalidad. Habana: Pueblo e Educación. (Trabalho original publicado em 1978).

Leontiev, A. N. (2004). O desenvolvimento do psiquismo. São Paulo: Centauro. (Trabalho original publicado em 1978).

Martins, L. M. (2004). A natureza histórico-social da personalidade. Caderno Cedes, 62 (24), 82-99.

Martins, L. M. (2007). A formação social da personalidade do professor: um enfoque vigotskiano. Campinas: Autores Associados.

Marx, K. (1998). Teses sobre Feuerbach. In: Marx, K. \& Engels, F. A ideologia alemã. (pp. 99-103). São Paulo: Martins Fontes. (Texto original publicado em 1845).

Molon, S. I. (2003). Subjetividade e constituição do sujeito em Vygotski. Petrópolis: Vozes.

Moraes, M. C. M. (2003). Recuo da Teoria. In: Moraes, M. C. M. (Org.). Iluminismo às avessas: produção de conhecimento e politicas de formação docente. (pp. 151-168). Rio de Janeiro: DP\&A, 2003.

Saviani, D. (2004). Perspectiva marxiana do problema subjetividadeintersubjetividade. In: Duarte, N. (Org.). Crítica ao fetichismo da individualidade. (pp. 21-52). Campinas: Autores Associados.

Silva, F. G. (2007). O professor e a educação: entre o prazer, o sofrimento e o adoecimento. Tese de doutorado, Programas de Pós-graduação em Psicologia da Educação, Pontifícia Universidade Católica de São Paulo, São Paulo. 
Vigotsky, L. S. (1988). Aprendizagem e desenvolvimento intelectual na idade escolar. In: Leontiev, A. N., Luria, A. R., Vigotskii, L. S. Linguagem, desenvolvimento e aprendizagem. (pp. 103-117). São Paulo: Ícone; Edusp. (Trabalho original publicado em 1933).

Vigotsky, L. S. \& Luria, A. R. (1996). Estudos sobre a história do comportamento: $o$ macaco, o primitivo e a criança. Porto Alegre: Artmed. (Trabalho original publicado em 1930).

Vigotsky, L. S. (2000). Obras escogidas III. Madri: Visor. (Trabalho original publicado em 1931). 